\title{
Mechanical properties of lightweight aerated concrete with different aluminium powder content
}

\author{
Rana Shabbar ${ }^{1,2,{ }^{*}}$, Paul Nedwell ${ }^{1}$, and Zhangjian $\mathrm{Wu}^{1}$ \\ ${ }^{1}$ School of Mechanical, Aerospace and Civil Engineering, University of Manchester, M13 9PL, UK \\ ${ }^{2}$ School of Engineering, University of Kufa, Najaf, Iraq
}

\begin{abstract}
Aerated concrete is produced by introducing gas into a concrete, the amount dependent upon the requirements for strength. One method to achieve this is by using powdered aluminium which reacts with the calcium hydroxide produced upon hydration of the cement. The aim of the current study was to investigate the influence of the powder content on the mechanical properties of aerated concrete namely; compressive and flexural strengths, modulus of elasticity, density and porosity. The results indicated that an increase in aluminium content caused a decrease in the compressive and tensile strengths. It also produced a decrease in the modulus of elasticity. When the aluminium content increased, the density decreased and the porosity increased.
\end{abstract}

\section{Introduction}

Aerated concrete $(\mathrm{AC})$ is produced by introducing gas bubbles into a conventional concrete which then produces a material of lower density. The introduction of powdered aluminium (a foaming agent) reacts with the calcium hydroxide formed on hydration of cement to produce hydrogen gas bubbles. It is not only used to insulate for sound and heat $[1,2]$ but is also fire resistance $[3,4]$. AC can be used to decrease the dead load, earthquake effect and the size of building members. Thus, foundations become more economical and the building cost is decreased $[5,6]$. However, this type of concrete has lower mechanical properties and additional cement is required for the same strength as a normal concrete [7]. Typical lightweight concrete has densities from 1000 to $2000 \mathrm{~kg} / \mathrm{m}^{3}$ and compressive strengths from 1 to $100 \mathrm{~N} / \mathrm{mm}^{2}[7]$.

Several investigations have been carried out regarding the influence of aluminium (Al) content on the compressive strength of aerated concrete [8-10]. Modulus of elasticity and flexural strength of lightweight concrete with different percentages of pumice aggregate replacement instead of sand [11] and AC with varying blocks and bricks (aerated concrete, solid and hollow block, moulded and wire cut brick) were also studied [12, 13]. Some studies into the density and porosity of AC have also been reported [10,13, 14]. The current study,

\footnotetext{
*Rana Shabbar: rana.shubber@uokufa.edu.iq / rana.shabbar@postgrad.manchester.ac.uk
} 
using laboratory testing, aims to provide a better understanding of the effect of $\mathrm{Al}$ concentration on the compressive and flexural strengths, modulus of elasticity, density and porosity of aerated concrete. A control of $0 \%$ will be compared with $0.25 \%, 0.5 \%, 0.75 \%$ and $1 \%$ content of $\mathrm{Al}$.

\section{Experimental details}

\subsection{Materials}

AC composed of one part of CEM I/52.5N with two parts of Leighton Buzzard sand together with Al with the purity of $99.7 \%$. The mix proportions of varying AC are shown in Table 1.

Table 1. Mix proportions of the $\mathrm{AC}$ with different $\mathrm{Al}$ contents.

\begin{tabular}{|l|c|c|c|c|c|}
\hline \multirow{2}{*}{\multicolumn{1}{c|}{ Material }} & \multicolumn{5}{c|}{$\mathbf{k g} / \mathbf{m}^{3}$} \\
\cline { 2 - 6 } & Mix 1 & Mix 2 & Mix 3 & Mix 4 & Mix 5 \\
\hline Cement & 350 & 350 & 350 & 350 & 350 \\
\hline Sand & 700 & 700 & 700 & 700 & 700 \\
\hline Water & 175 & 175 & 175 & 175 & 175 \\
\hline Aluminium powder & 0 & 0.87 & 1.75 & 2.63 & 3.5 \\
\hline Superplasticizer (SP) & 4.2 & 4.2 & 4.2 & 4.2 & 4.2 \\
\hline
\end{tabular}

\subsection{Procedure}

First, cement and sand were mixed together. Then aluminum powder was added and mixed for $30 \mathrm{sec}$. Finally, warm water $\left(55 \pm 1{ }^{\circ} \mathrm{C}\right)$ with the superplasticizer were added and mixed for $2 \mathrm{~min}$.

\subsection{Casting and testing}

$100 \mathrm{~mm}$ cube was used for compression test. The compressive strength of the AC was determined according to the BS EN $1881-116$ [15]. Flexural strength was measured by using prisms with dimensions $40 \mathrm{~mm}$ cross section and $160 \mathrm{~mm}$ length according to the BS EN 1351 [16]. Cylinders with diameter $100 \mathrm{~mm}$ and length $200 \mathrm{~mm}$ were used for determined modulus of elasticity $\left(\mathrm{E}_{\mathrm{s}}\right)$ according to BS EN 1352 [17]. The dry density of the AC was measured according to the BS EN 992 [18]. Porosity was measured by vacuum saturation method according to Hall [19].

\section{Test results and discussion}

\subsection{Compressive strength}

In this study, the compressive strength of $\mathrm{AC}$ mixtures was a function of different $\mathrm{Al}$ contents, which are plotted in Figure 1, and presented lower strengths when compared with the control. The lowest compressive strength was $18.6 \mathrm{~N} / \mathrm{mm}^{2}$ with $1 \% \mathrm{Al}$ due to largest number of voids and lowest rate of calcium silicate hydrate (C-S-H) gel. Thus, it did not contribute sufficiently to the compressive strength. The highest strength was for control $(0 \%$ $\mathrm{Al}$ ) at $53 \mathrm{~N} / \mathrm{mm}^{2}$ which then decreased significantly on introduction of $0.25 \%$ Al to 32.3 $\mathrm{N} / \mathrm{mm}^{2}$ and then decreased slightly as the $\mathrm{Al}$ increased with $26 \mathrm{~N} / \mathrm{mm}^{2}$ for $0.5 \%$ and 23.4 
$\mathrm{N} / \mathrm{mm}^{2}$ for $0.75 \% \mathrm{Al}$. Similar results were obtained by Guglielmi et al. [8] who reported that when the $\mathrm{Al}$ content increased from 0.2 to $0.4 \%$, the compressive strength decreased because of the higher homogeneous distribution and quantity of the pores and the inter-pore struts are thinner, conferring a lower strength to the material.

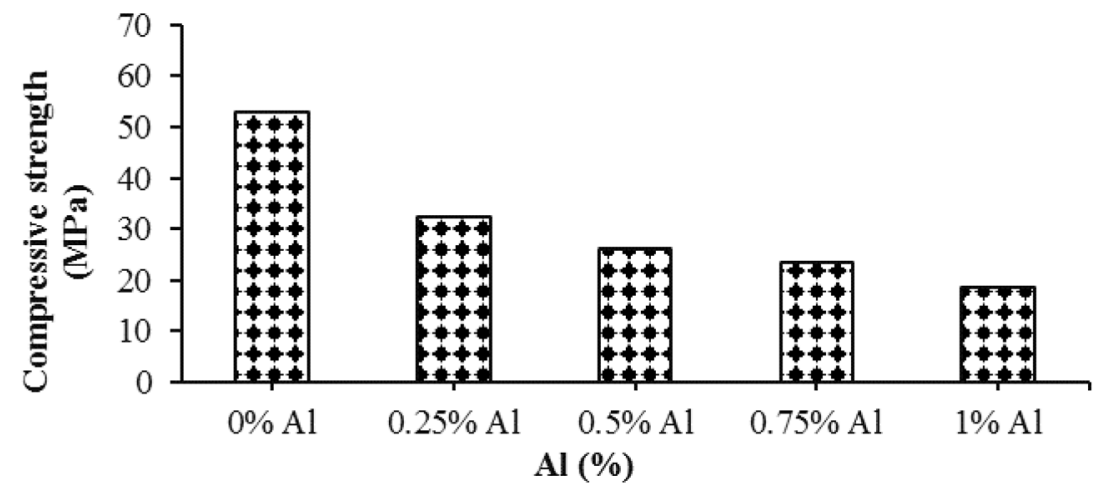

Fig. 1. Compressive strength of cube $\mathrm{AC}$ specimens as a function of $\mathrm{Al}$ content.

\subsection{Flexural strength}

The variations of the flexural strength of AC are presented in Figure 2 which shows that it decreases when the Al content increases. The lowest flexural strength was $3.3 \mathrm{MPa}$ with $1 \%$ Al. The highest strength was for control $(0 \% \mathrm{Al})$ at $5.5 \mathrm{MPa}$ which then decreased slightly on introduction of $0.25 \% \mathrm{Al}$ to $4.6 \mathrm{MPa}, 4.2 \mathrm{MPa}$ for $0.5 \%$ and $3.7 \mathrm{MPa}$ for $0.75 \% \mathrm{Al}$. Similar results were obtained by $[20,21]$, when the flexural strength increased due to an increase in compressive strength.

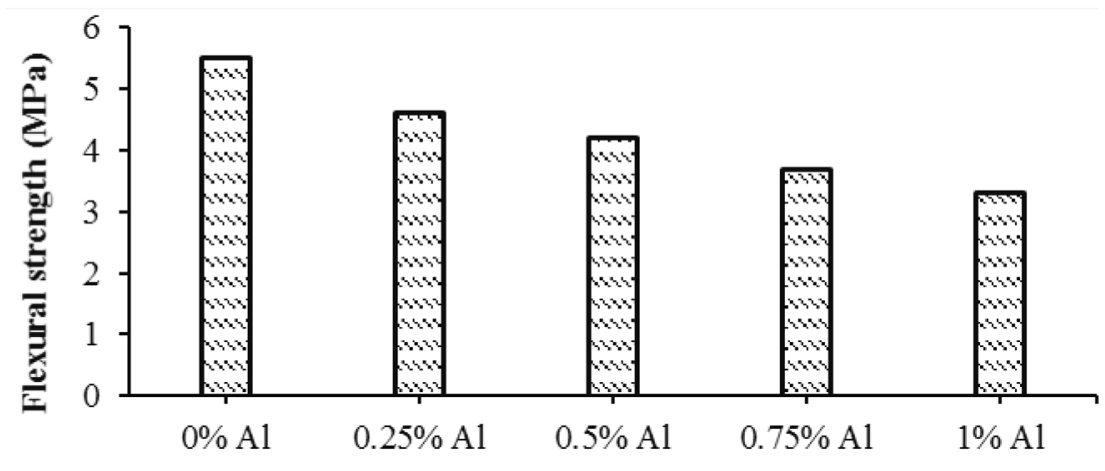

Al (\%)

Fig. 2. Flexural strength of $\mathrm{AC}$ as a function of $\mathrm{Al}$ content.

\subsection{Modulus of elasticity}

The modulus of elasticity (Es) is mainly effected by the nature of the aggregates and cement paste. Additional effects are provided by the bond and arrangement between the particles [22]. Figure 3 presents the modulus of elasticity of AC with different Al content. In comparison to control, AC specimens have less stiffness due to the presence of the $\mathrm{Al}$, which caused larger and more pores to be formed and reducing strength. It is clear that the AC which is obtained from high $\mathrm{Al}$ powder content caused a greater loss in the modulus of 
elasticity than that with lower content. The lowest Es was 7.8 MPa with $1 \% \mathrm{Al}$. The highest Es was for control $(0 \% \mathrm{Al})$ at $23 \mathrm{MPa}$ which then decreased slightly on introduction of $0.25 \%$ Al to $18.9 \mathrm{MPa}, 14.1 \mathrm{MPa}$ for $0.5 \%$ and $9.7 \mathrm{MPa}$ for $0.75 \% \mathrm{Al}$.

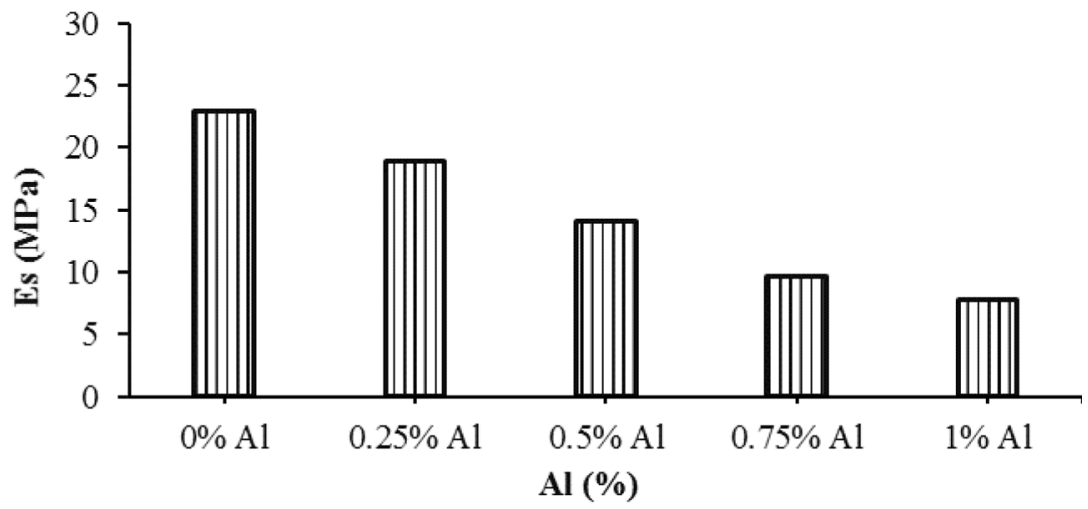

Fig. 3. Modulus of elasticity of $\mathrm{AC}$ as a function of $\mathrm{Al}$ content.

\subsection{Density and porosity}

The dry density and the porosity of AC samples are both a function of $\mathrm{Al}$ powder content as shown in Figure 4. The result revealed that the dry density varied as expected for the different $\mathrm{Al}$ contents. It decreased as the foaming agent percentage increased because of the higher number of pores created. The density decreased from $2102 \mathrm{Kg} / \mathrm{m}^{3}$ for the control to 1841 $\mathrm{Kg} / \mathrm{m}^{3}$ with $0.25 \% \mathrm{Al}$ powder. Then it decreased gradually with the increasing Al content. The lowest density was obtained with $1 \% \mathrm{Al}$ which was $1489 \mathrm{Kg} / \mathrm{m}^{3}$. The same behaviour was observed for the porosity of the AC samples which increased from $10 \%$ to $26 \%$ when the $\mathrm{Al}$ content increased from $0 \%$ to $1 \%$. AC samples with $\mathrm{Al}$ powder from 0.5 to $1 \%$ revealed the present of pores with a non-uniform shape. These were larger than those observed for AC with $0.25 \% \mathrm{Al}$, which indicates the coalescence of the pores in mixtures with higher Al content. Scheffler and Colombo explained the coalescence of the pore to the high reactivity of the Al powder [23]. The fracture surfaces of the AC samples with different Al contents in this study are shown in Figure 5.

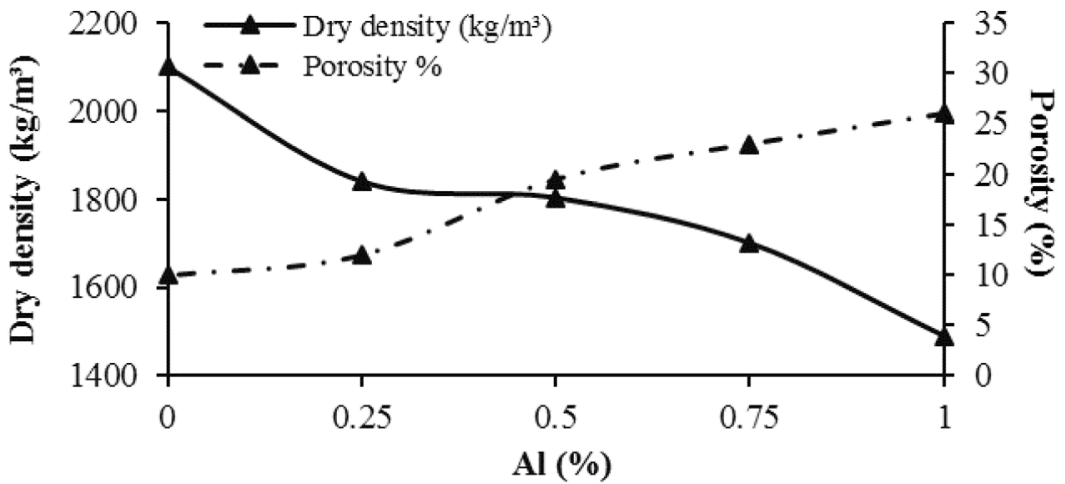

Fig. 4. Apparent density and porosity of $\mathrm{AC}$ as a function of $\mathrm{Al}$ content. 


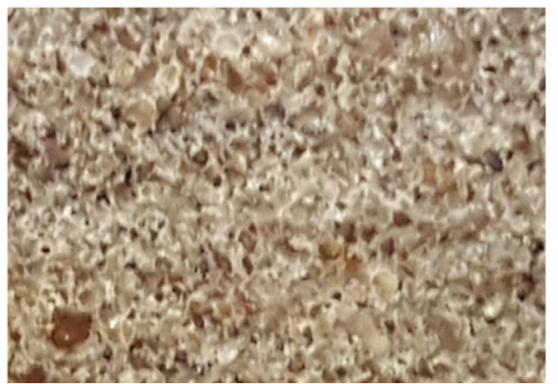

A. Control (0\% Al)

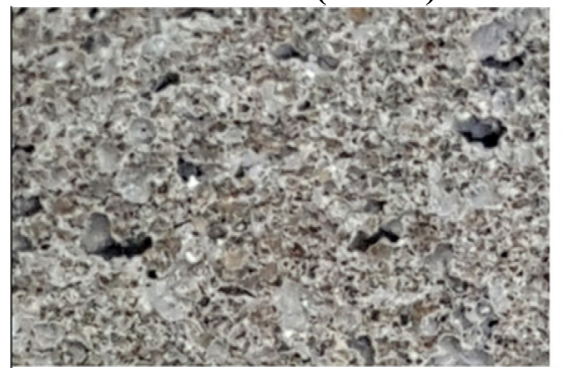

C. $0.5 \%$ Al

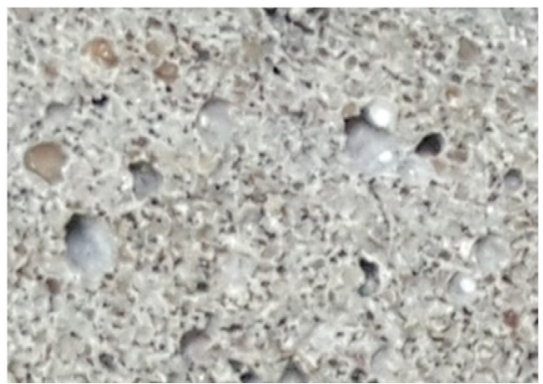

B. $0.25 \% \mathrm{Al}$

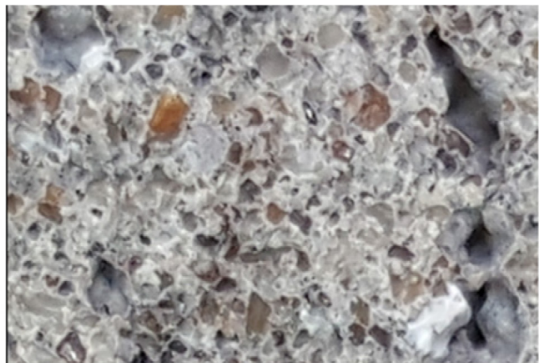

D. $0.75 \% \mathrm{Al}$

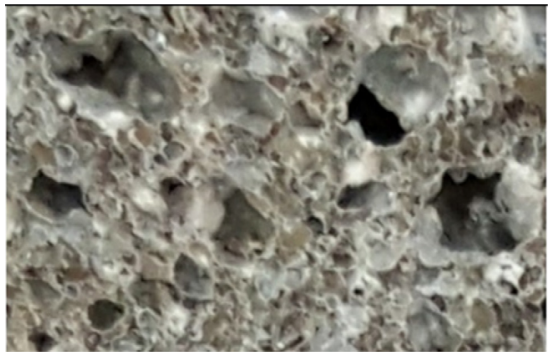

E. $1 \% \mathrm{Al}$

Fig. 5. Fracture surface of AC samples with different $\mathrm{Al}$ content.

\section{Conclusion}

This study has shown that by adding Al powder:

1. The compressive strength of the AC specimens decreases with increasing the $\mathrm{Al}$ powder content. Due to the high reactivity of $\mathrm{Al}$, the rate of production calcium silicate hydrate (C-S-H) gel may decrease which corresponds with the reduction in the strength.

2. The flexural strength of the $\mathrm{AC}$ has direct relationship with compressive strength results and it decreases as the foaming agent increases.

3. The modulus of elasticity of the AC specimens declined according to the increase of the content of the Al.

4. When the Al powder content increased, the density decreased gradually. However, the porosity increased significantly due to higher number of pores formed (Fig.5). 
5. The fractured surfaces of the AC samples with the Al powder from 0.5 to $1 \%$ revealed the present of the pores with a non-uniform shape, which were larger than those observed for AC with low content $0.25 \%$.

The authors are grateful for financial support of the Iraqi ministry of high education and scientific research (MOHESR), my colleague Mr. Mohammed Al-Taee and technician support of Mr. John Mason in the school of MACE, University of Manchester.

\section{References}

1. A. Aidan, et al., Preparation and properties of porous aerated concrete. Scientific Works of the University of Ruse, 48, 9 (2009)

2. A. J. Hamad, Materials, Production, Properties and Application of Aerated Lightweight Concrete: Review. International Journal of Materials Science and Engineering, 2, 2 (2004)

3. N. Narayanan and K. Ramamurthy, Structure and properties of aerated concrete: a review, Cement and Concrete Composites, 22, 5 (2000)

4. A. Keyvani1, Thermal performance \& fire resistance of autoclaved aerated concrete exposed humidity conditions. International Journal of Research in Engineering and Technology, 3, 3 (2014)

5. D. H. Lim and B.H. Oh, Experimental and theoretical investigation on the shear of steel fibre reinforced concrete beams. Engineering Structures, 21, 10 (1999)

6. O. A. Düzgün, R. Gül, and A. C. Aydin, Effect of steel fibers on the mechanical properties of natural lightweight aggregate concrete. Materials Letters, 59, 27 (2005)

7. A. M. Neville and J. J. Brooks, Concrete technology. 2nd ed. Harlow: Longman Scientific \& Technical (2010)

8. P. O. Guglielmi, et al., Porosity and Mechanical Strength of an Autoclaved Clayey Cellular Concrete. Advances in Civil Engineering (2010)

9. I. S. Raj and E. John, A Study on the Properties of Air-Entrained Concrete for Masonry Blocks. International Journal of Scientific Engineering and Technology. 3, 11 (2014)

10. A. A. Aliabdo, A.-E.M. Abd-Elmoaty, and H. H. Hassan, Utilization of crushed clay brick in cellular concrete production. Alexandria Engineering Journal. 53, 1 (2014)

11. R. Şahin, et al., The effects of different cement dosages, slumps and pumice aggregate ratios on the compressive strength and densities of concrete. Cement and Concrete Research. 33, 8 (2003)

12. A. Ahmed and A. Fried, Flexural strength of low density blockwork. Construction and Building Materials. 35, p. 516-520 (2012)

13. T. M. Prakash, et al., Properties of Aerated (Foamed) Concrete Blocks International Journal of Scientific \& Engineering Research. 4, 1 (2013)

14. K. H. Yang and K. H. Lee, Tests on high-performance aerated concrete with a lower density. Construction and Building Materials. 74, p. 109-117 (2015)

15. BS EN 1881-116, Testing concrete. Method for determination of compressive strength of concrete cubes (1983)

16. BS EN 1351, Determination of flexural strength of autoclaved aerated concrete (1997)

17. BS EN 1352, Determination of static modulus of elasticity under compression of autoclaved aerated concrete or lightweight aggregate concrete with open structure (1997)

18. BS EN 992, Determination of the dry density of lightweight aggregate concrete with open structure (1996)

19. C. Hall, Water transport in brick, stone and concrete, ed. W.D. Hoff. London: E. \& F. N. Spon (2000) 
20. N. B. Eden, et al., Autoclaved aerated concrete from slate waste Part 1: Some property/density relationships. International Journal of Cement Composites and Lightweight Concrete. 2, 2 (1980)

21. T. M. Prakash, B. G. N. Kumar and Karisiddappa, Strength and elastic properties of aerated concrete block masonry. International Journal of Structural and Civil Engineering Research. 2, 1 (2013)

22. R. V. Silva, J. de Brito and R. K. Dhir, Establishing a relationship between modulus of elasticity and compressive strength of recycled aggregate concrete. Journal of Cleaner Production. 112, Part 4 (2016)

23. M. Scheffler and P. Colombo, Cellular ceramics: structure, manufacturing, properties and applications, ed. M. Scheffler and P. Colombo. Weinheim: Chichester: Weinheim: Wiley-VCH Chichester: John Wiley distributor (2005) 